\title{
ABSOLUTE PROPERTIES OF THE BINARY SYSTEM BB PEGASI
}

\author{
B. Kalomeni, ${ }^{1}$ K. Yakut, ${ }^{2,3}$ V. Keskin, ${ }^{2}$ Ö. L. DeĞIRmenci, ${ }^{2}$ B. Ulaș, ${ }^{4,5}$ and O. Köse ${ }^{2}$ \\ Received 2007 January 20; accepted 2007 May 2
}

\begin{abstract}
We present ground-based photometry of the low-temperature contact binary BB Peg. We collected all the times of mid-eclipse available in the literature and combined them with those obtained in this study. Analyses of the data indicate a period increase of $(3.0 \pm 0.1) \times 10^{-8}$ days $\mathrm{yr}^{-1}$. This period increase of BB Peg can be interpreted in terms of the mass transfer $2.4 \times 10^{-8} M_{\odot} \mathrm{yr}^{-1}$ from the less massive to the more massive component. The physical parameters have been determined as $M_{c}=1.42 M_{\odot}, M_{h}=0.53 M_{\odot}, R_{c}=1.29 R_{\odot}, R_{h}=0.83 R_{\odot}, L_{c}=1.86 L_{\odot}$, and $L_{h}=0.94 L_{\odot}$ through simultaneous solutions of light and of the radial velocity curves. The orbital parameters of the third body, which orbits the contact system in an eccentric orbit, were obtained from the period variation analysis. The system is compared to the similar binaries in the Hertzsprung-Russell and mass-radius diagrams.
\end{abstract}

Key words: binaries: close — binaries: eclipsing — stars: individual (BB Pegasi) — stars: late-type

Online material: color figures, machine-readable table

\section{INTRODUCTION}

BB Peg (HIP 110493; $V=11.6 \mathrm{mag}, \mathrm{F} 8 \mathrm{~V}$ ) is a lowtemperature contact binary (LTCB) system which was discovered as a variable star in 1931 by Hoffmeister (1931). Whitney (1959) refined the orbital period. Since then BB Peg has been the subject of several investigations. The system was observed photoelectrically in 1978 by Cerruti-Sola \& Scaltriti (1980), Zhai \& Zhang (1979), and Awadalla (1988). The times of minima of the system have been published by numerous authors.

Cerruti-Sola et al. (1981) analyzed the $B V$ light curves of Cerruti-Sola \& Scaltriti (1980) using the Wilson-Devinney (WD; Wilson \& Devinney 1971) code. Giuricin et al. (1981) solved the same light curves using the Wood (1972) model and obtained somewhat different results. Leung et al. (1985) used WD to analyze the $B V$ light curves obtained by Zhai \& Zhang (1979). Awadalla (1988) observed $U B V$ light curves but did not perform a light-curve analysis. The mass ratio was determined photometrically for these light-curve solutions. The first radial velocity study of the system done by Hrivnak (1990) gives the mass ratio as $0.34 \pm 0.02$. More recent radial velocity data obtained by Lu \& Rucinski (1999) result in a mass ratio of $0.360 \pm$ 0.006 . The photometric mass ratio $(0.360 \mp 0.003)$ derived by Leung et al. (1985) agrees very well with the spectroscopic value, a result of the total/annular nature of the eclipses (see Terrell \& Wilson 2005). Zola et al. (2005) published the physical parameters of the components. The orbital period variation was studied by Cerruti-Sola \& Scaltriti (1980) and Qian (2001).

\section{OBSERVATIONS}

The photometric observations of the system were obtained with the $0.4 \mathrm{~m}$ ( T40), $0.35 \mathrm{~m}$ ( T35), and $0.30 \mathrm{~m}$ telescopes ( T30) at the Ege University Observatory and TÜBITAK National Observatory on eight nights during the observing season between

\footnotetext{
${ }^{1}$ Department of Physics, İzmir Institute of Technology, İzmir, Turkey.

2 Department of Astronomy and Space Sciences, University of Ege, İzmir, Turkey.

3 Institute of Astronomy, Katholieke Universiteit Leuven, Leuven, Belgium.

${ }^{4}$ Department of Physics, Onsekiz Mart University of Çanakkale, Çanakkale, Turkey.

${ }^{5}$ Department of Astrophysics, Astronomy and Mechanics, University of Athens, Athens, Greece.
}

August and December 2004 with T35 and two nights in 2006 with T40. However, the system was observed at T30 and T40 for only three nights in order to obtain the minimum times. The light curve of the system was obtained from CCD photometry observations. The light curves of BB Peg in the Bessel $V$ and $R$ filters are shown in Figure $2 d$ (discussed in $\S 4$ ), and the data are given in Table 1 . The comparison and check stars were BD +154634 and GSC 01682-01530, respectively.

We obtained two minimum times throughout these observations. They are listed in Table 2, together with those published in the existing literature. Using these minimum times we derived the linear ephemeris

$$
\text { HJD Min. } \mathrm{I}=2,450,657.4599(4)+0.3615015(1) E
$$

and used it in the reduction processes of the observed data.

\section{ECLIPSE TIMINGS AND PERIOD STUDY}

The period variation study of the system was presented for the first time by Cerruti-Sola \& Scaltriti (1980), resulting in the ephemeris Min. I $(\mathrm{HJD})=2,443,764.3334(6)+0.3615021(2) E+$ $\left(2.3 \times 10^{-11}\right) E^{2}$. Qian (2001) presented it as Min. I $($ HJD $)=$ $2,430,285.7618(6)+0.36150027(1) E+[(2.35 \pm 0.01) \times$ $\left.10^{-11}\right] E^{2}$.

Recently, the existence of a third body was reported via spectroscopic study by D'Angelo et al. (2006). We used the linear ephemeris given by Qian (2001) to construct the binary's $O-C$ diagram. It shows almost a sine-like variation superposed on an upward parabola. A sine-like variation in the $O-C$ curve, where both the primary and the secondary minima follow the same trend, suggests the light-time effect via the presence of a tertiary component. Times of minima of BB Peg yielded the following equation:

$$
\begin{aligned}
\text { Min. I }= & T_{0}+P_{0} E+\frac{1}{2} \frac{d P}{d E} E^{2}+\frac{a_{12} \sin i^{\prime}}{c} \\
& \times\left[\frac{1-e^{\prime 2}}{1+e^{\prime} \cos v^{\prime}} \sin \left(v^{\prime}+\omega^{\prime}\right)+e^{\prime} \sin \omega^{\prime}\right],
\end{aligned}
$$

where $T_{0}$ is the starting epoch for the primary minimum; $E$ is the integer eclipse cycle number; $P_{0}$ is the orbital period of the 
TABLE 1

VR Measurements of BB Peg

\begin{tabular}{cccc}
\hline \hline HJD & Phase & $\Delta m$ & Filter \\
\hline $53,301.3054 \ldots \ldots \ldots \ldots \ldots$. & 0.5115 & 1.2930 & 1 \\
$53,301.3067 \ldots \ldots \ldots \ldots \ldots$. & 0.5151 & 1.2840 & 1 \\
$53,301.3080 \ldots \ldots \ldots \ldots \ldots$. & 0.5187 & 1.2610 & 1 \\
$53,301.3093 \ldots \ldots \ldots \ldots \ldots$. & 0.5224 & 1.2500 & 1 \\
$53,301.3106 \ldots \ldots \ldots \ldots \ldots$. & 0.5260 & 1.2300 & 1 \\
$53,301.3119 \ldots \ldots \ldots \ldots \ldots$ & 0.5296 & 1.2050 & 1 \\
$53,301.3133 \ldots \ldots \ldots \ldots \ldots$. & 0.5333 & 1.1840 & 1 \\
$53,301.3146 \ldots \ldots \ldots \ldots \ldots$. & 0.5369 & 1.1690 & 1 \\
$53,301.3159 \ldots \ldots \ldots \ldots \ldots$. & 0.5405 & 1.1560 & 1 \\
\hline
\end{tabular}

Notes.-See Fig. $2 d$. The phases were calculated using eq. (1). In the fourth column, 1 and 2 denote the $V$ and $R$ filters, respectively. Table 1 is published in its entirety in the electronic edition of the Astronomical Journal. A portion is shown here for guidance regarding its form and content.

eclipsing binary; $a_{12}, i^{\prime}, e^{\prime}$, and $\omega^{\prime}$ are the semimajor axis, inclination, eccentricity, and longitude of periastron of the eclipsing pair about the third body; and $v^{\prime}$ is the true anomaly of the position of the center of mass. Time of periastron passage $T^{\prime}$ and orbital period $P^{\prime}$ are unknown parameters in equation (2).

Light elements in equation (2) were determined using the differential correction method. We used equation (2), along with the values given in Table 2 and a weighted least-squares solution, to derive the parameters shown in Table 3 . We assigned weight 10 to photoelectric (pe), 1 to photographic (pg), and $0(\mathrm{pg})$ to a few cases that show high deviation from the expected normal position (Fig. 1b, open circles). The parameters given in Table 3 were used for the $\triangle T_{\mathrm{I}}$ variation study of the system, which is plotted in Figure $1 a$. The $O-C$ values in this figure were obtained with the linear elements $T_{0}$ and $P_{0}$ given in Table 3 . The solid line in Figure $1 a$ shows the secular increase of the binary's orbital period, while the dashed line shows both the secular increase and the light-time effect of the tertiary component. We also present the contribution of the light-time effect, $\triangle T_{\mathrm{II}}$, to total period variations of the system in Figure $1 b$. In the last section of this study we discuss the tertiary component in BB Peg.

\section{LIGHT-CURVE ANALYSIS}

Previous light curves have been analyzed either by old methods or with the assumption that the photometric mass ratio was known. All previously published light curves, as well as those of the current study, have been analyzed simultaneously with the Lu \& Rucinski (1999) radial velocities using the latest version of the WD code (Wilson \& Devinney 1971; Wilson 1994). Mode 3 of the WD code has been used throughout the analysis. As seen in Figure 2, the light curves show asymmetries in the maxima. Generally, it is accepted that stellar activity may cause these asymmetries in the light curves; we discuss these asymmetries in $\S 5$. Hence, the stellar spot parameters were taken into consideration

TABLE 2

The Primary (I) and Secondary (II) Minima Times in HJD

\begin{tabular}{|c|c|c|c|c|c|c|c|c|}
\hline HJD & Min. & Ref. & HJD & Min. & Ref. & HJD & Min. & Ref. \\
\hline 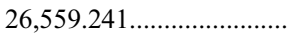 & II & 1 & 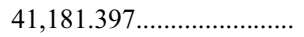 & $\mathrm{I}$ & 5 & $50,657.4575 \ldots \ldots \ldots \ldots \ldots \ldots \ldots$ & $\mathrm{I}$ & 16 \\
\hline $26,582.014 \ldots \ldots \ldots \ldots \ldots \ldots \ldots$ & II & 2 & 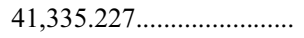 & II & 6 & $50,671.3770 \ldots \ldots \ldots \ldots \ldots \ldots$ & II & 16 \\
\hline $26,965.204 \ldots \ldots \ldots \ldots \ldots \ldots \ldots \ldots$ & II & 2 & $42,405.259 \ldots \ldots \ldots \ldots \ldots \ldots \ldots \ldots \ldots \ldots \ldots$ & II & 7 & $50,702.4698 \ldots \ldots \ldots \ldots \ldots \ldots \ldots$ & II & 17 \\
\hline $27,393.223 \ldots \ldots \ldots \ldots \ldots \ldots \ldots \ldots$ & II & 2 & $42,607.523 \ldots \ldots \ldots \ldots \ldots \ldots \ldots$ & $\mathrm{I}$ & 8 & $50,739.7052 \ldots \ldots \ldots \ldots \ldots \ldots \ldots$ & II & 18 \\
\hline $30,226.826 \ldots \ldots \ldots \ldots \ldots \ldots \ldots$ & $\mathrm{I}$ & 3 & $42,748.310 \ldots \ldots \ldots \ldots \ldots \ldots \ldots \ldots$ & II & 8 & $50,769.525 \ldots \ldots \ldots \ldots \ldots \ldots \ldots \ldots \ldots \ldots \ldots \ldots \ldots \ldots$ & $\mathrm{I}$ & 18 \\
\hline $30,235.865 \ldots \ldots \ldots \ldots \ldots \ldots \ldots \ldots$ & $\mathrm{I}$ & 3 & $43,729.4491 \ldots \ldots \ldots \ldots \ldots \ldots \ldots$ & II & 9 & $51,078.4304 \ldots \ldots \ldots \ldots \ldots \ldots \ldots$ & II & 19 \\
\hline 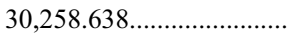 & $\mathrm{I}$ & 3 & $43,730.3512 \ldots \ldots \ldots \ldots \ldots \ldots \ldots$ & $\mathrm{I}$ & 9 & $51,471.3810 \ldots \ldots \ldots \ldots \ldots \ldots \ldots$ & II & 20 \\
\hline $30,264.797 \ldots \ldots \ldots \ldots \ldots \ldots \ldots$ & $\mathrm{I}$ & 3 & $43,754.3896 \ldots \ldots \ldots \ldots \ldots \ldots . .$. & II & 9 & $52,131.8425 \ldots \ldots \ldots \ldots \ldots \ldots \ldots \ldots \ldots$ & II & 21 \\
\hline $30,281.776 \ldots \ldots \ldots \ldots \ldots \ldots \ldots \ldots$ & $\mathrm{I}$ & 3 & $43,754.3896 \ldots \ldots \ldots \ldots \ldots \ldots \ldots$ & I & 9 & $52,201.2508 \ldots \ldots \ldots \ldots \ldots \ldots \ldots$ & II & 22 \\
\hline $30,285.753 \ldots \ldots \ldots \ldots \ldots \ldots \ldots$ & $\mathrm{I}$ & 3 & 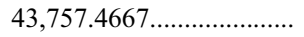 & $\mathrm{I}$ & 9 & $52,201.4305 \ldots \ldots \ldots \ldots \ldots \ldots . . . . . . .$. & $\mathrm{I}$ & 22 \\
\hline $30,530.861 \ldots \ldots \ldots \ldots \ldots \ldots \ldots$ & $\mathrm{I}$ & 3 & $43,764.3334 \ldots \ldots \ldots \ldots \ldots \ldots . .$. & $\mathrm{I}$ & 9 & $52,203.2386 \ldots \ldots \ldots \ldots \ldots \ldots . . . . . . . . .$. & $\mathrm{I}$ & 22 \\
\hline $30,552.903 \ldots \ldots \ldots \ldots \ldots \ldots \ldots$ & $\mathrm{I}$ & 3 & $43,806.08453 \ldots \ldots \ldots \ldots \ldots \ldots$ & II & 10 & $52,203.4188 \ldots \ldots \ldots \ldots \ldots \ldots$ & II & 22 \\
\hline $30,584.721 \ldots \ldots \ldots \ldots \ldots \ldots \ldots$ & $\mathrm{I}$ & 3 & $43,806.98838 \ldots \ldots \ldots \ldots \ldots \ldots$ & $\mathrm{I}$ & 10 & $52,207.3962 \ldots \ldots \ldots \ldots \ldots \ldots . . . . . . .$. & II & 22 \\
\hline 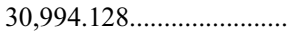 & II & 2 & $43,813.13365 \ldots \ldots \ldots \ldots \ldots \ldots . .$. & $\mathrm{I}$ & 10 & $52,513.4118 \ldots \ldots \ldots \ldots \ldots \ldots \ldots \ldots \ldots \ldots$ & $\mathrm{I}$ & 23 \\
\hline 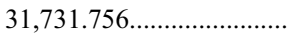 & $\mathrm{I}$ & 4 & 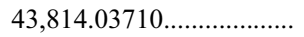 & II & 10 & $52,838.402 \ldots \ldots \ldots \ldots \ldots \ldots \ldots \ldots \ldots \ldots \ldots \ldots \ldots$ & I & 24 \\
\hline $31,783.455 \ldots \ldots \ldots \ldots \ldots \ldots \ldots$ & $\mathrm{I}$ & 4 & $43,842.05373 \ldots \ldots \ldots \ldots \ldots \ldots$ & $\mathrm{I}$ & 10 & $52,852.4956 \ldots \ldots \ldots \ldots \ldots \ldots$ & $\mathrm{I}$ & 25 \\
\hline $32,433.631 \ldots \ldots \ldots \ldots \ldots \ldots \ldots \ldots$ & II & 4 & $43,866.99893 \ldots \ldots \ldots \ldots \ldots \ldots . .$. & $\mathrm{I}$ & 10 & $53,243.4607 \ldots \ldots \ldots \ldots \ldots \ldots \ldots$ & II & 26 \\
\hline $32,433.801 \ldots \ldots \ldots \ldots \ldots \ldots \ldots$ & I & 4 & $44,812.503 \ldots \ldots \ldots \ldots \ldots \ldots \ldots . .$. & II & 11 & $53,284.3112 \ldots \ldots \ldots \ldots \ldots \ldots \ldots$ & II & 22 \\
\hline $32,436.687 \ldots \ldots \ldots \ldots \ldots \ldots \ldots$ & $\mathrm{I}$ & 4 & $45,208.3511 \ldots \ldots \ldots \ldots \ldots \ldots \ldots$ & II & 12 & $53,285.3957 \ldots \ldots \ldots \ldots \ldots \ldots$ & II & 22 \\
\hline $32,436.866 \ldots \ldots \ldots \ldots \ldots \ldots \ldots \ldots$ & II & 4 & $45,208.5319 \ldots \ldots \ldots \ldots \ldots \ldots \ldots$ & $\mathrm{I}$ & 12 & $53,353.3577 \ldots \ldots \ldots \ldots \ldots \ldots \ldots$ & II & 26 \\
\hline 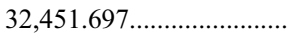 & II & 4 & $46,024.2600 \ldots \ldots \ldots \ldots \ldots \ldots \ldots$ & II & 12 & $53,984.3589 \ldots \ldots \ldots \ldots \ldots \ldots \ldots$ & $\mathrm{I}$ & 26 \\
\hline $32,455.683 \ldots \ldots \ldots \ldots \ldots \ldots \ldots$ & II & 4 & $46,026.2483 \ldots \ldots \ldots \ldots \ldots \ldots . .$. & $\mathrm{I}$ & 12 & 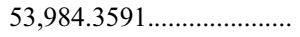 & $\mathrm{I}$ & 26 \\
\hline $32,473.567 \ldots \ldots \ldots \ldots \ldots \ldots \ldots \ldots$ & $\mathrm{I}$ & 4 & $49,243.4462 \ldots \ldots \ldots \ldots \ldots \ldots \ldots . .$. & II & 13 & $53,984.5409 \ldots \ldots \ldots \ldots \ldots \ldots \ldots$ & II & 26 \\
\hline $32,477.538 \ldots \ldots \ldots \ldots \ldots \ldots \ldots . .$. & $\mathrm{I}$ & 4 & 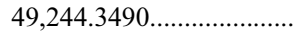 & $\mathrm{I}$ & 13 & $53,984.5411 \ldots \ldots \ldots \ldots \ldots \ldots \ldots$ & II & 26 \\
\hline $32,477.744 \ldots \ldots \ldots \ldots \ldots \ldots \ldots$ & II & 4 & 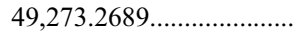 & $\mathrm{I}$ & 13 & 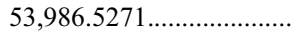 & I & 26 \\
\hline $32,479.710 \ldots \ldots \ldots \ldots \ldots \ldots \ldots \ldots$ & $\mathrm{I}$ & 4 & $49,275.2600 \ldots \ldots \ldots \ldots \ldots \ldots \ldots$ & II & 13 & $53,986.5276 \ldots \ldots \ldots \ldots \ldots \ldots \ldots \ldots \ldots \ldots$ & I & 26 \\
\hline $34,711.615 \ldots \ldots \ldots \ldots \ldots \ldots \ldots \ldots$ & $\mathrm{I}$ & 4 & $50,001.3351 \ldots \ldots \ldots \ldots \ldots \ldots \ldots$ & I & 14 & $53,992.4949 \ldots \ldots \ldots \ldots \ldots \ldots \ldots$ & II & 26 \\
\hline $35,468.604 \ldots \ldots \ldots \ldots \ldots \ldots \ldots$ & $\mathrm{I}$ & 4 & 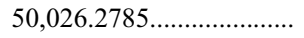 & $\mathrm{I}$ & 14 & 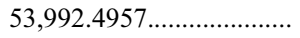 & II & 26 \\
\hline 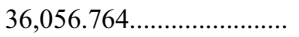 & $\mathrm{I}$ & 4 & $50,359.4028 \ldots \ldots \ldots \ldots \ldots \ldots \ldots$ & II & 15 & & & \\
\hline
\end{tabular}

Note.-HJD - 2,400,000.

REFERENCES.-(1) Zessewitsch 1939; (2) Tsessevich 1954; (3) Whitney 1943; (4) Whitney 1959; (5) Diethelm 1973; (6) Locher 1973; (7) Diethelm 1976; (8) Diethelm

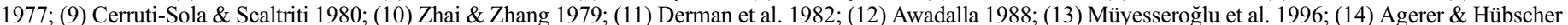

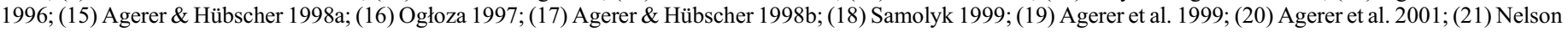
2002; (22) Drozdz \& Ogłoza 2005; (23) Demircan et al. 2003; (24) Bakıș et al. 2003; (25) Hübscher 2005; (26) this work. 
TABLE 3

Orbital Elements of the Tertiary Component in BB Peg

\begin{tabular}{|c|c|}
\hline Parameter & Value \\
\hline$T_{0}(\mathrm{HJD}) \ldots \ldots \ldots \ldots$ & $2,430,285.7655(36)$ \\
\hline 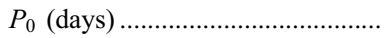 & $0.3615006(1)$ \\
\hline 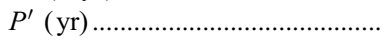 & $27.9(2.0)$ \\
\hline$T^{\prime}(\mathrm{HJD}) \ldots \ldots \ldots \ldots$ & $2,438,540(793)$ \\
\hline 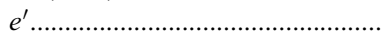 & $0.56(0.30)$ \\
\hline$\omega^{\prime}(\operatorname{deg}) \ldots \ldots \ldots \ldots . .$. & $69(18)$ \\
\hline 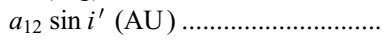 & $0.96(15)$ \\
\hline 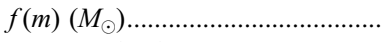 & $0.0010(5)$ \\
\hline$m_{3 ; i^{\prime}=10^{\circ}}\left(M_{\odot}\right) \ldots \ldots \ldots \ldots \ldots \ldots \ldots \ldots \ldots \ldots \ldots \ldots \ldots \ldots \ldots \ldots$ & 1.23 \\
\hline 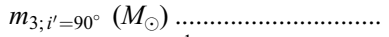 & 0.16 \\
\hline$Q\left(\right.$ counts day $\left.{ }^{-1}\right) \ldots \ldots \ldots \ldots \ldots \ldots \ldots \ldots \ldots \ldots \ldots \ldots \ldots \ldots$ & $1.5(2) \times 10^{-11}$ \\
\hline
\end{tabular}

NotE.-The standard errors $(1 \sigma)$ in the last digit are given in parentheses.

in our analysis. The adopted values are $T_{1}=6250 \mathrm{~K}$ and, according to the $B-V$ color index, gravity-darkening coefficients and albedos were chosen as $g_{1}=g_{2}=0.32$ (Lucy 1967) and $A_{1}=$ $A_{2}=0.5$ (Rucinski 1969) and the logarithmic limb-darkening coefficients $\left(x_{1}, x_{2}\right)$ were obtained from van Hamme (1993). The semimajor axis of the relative orbit $a$, binary center-of-mass radial velocity $V_{\gamma}$, inclination $i$, temperature of the secondary com-
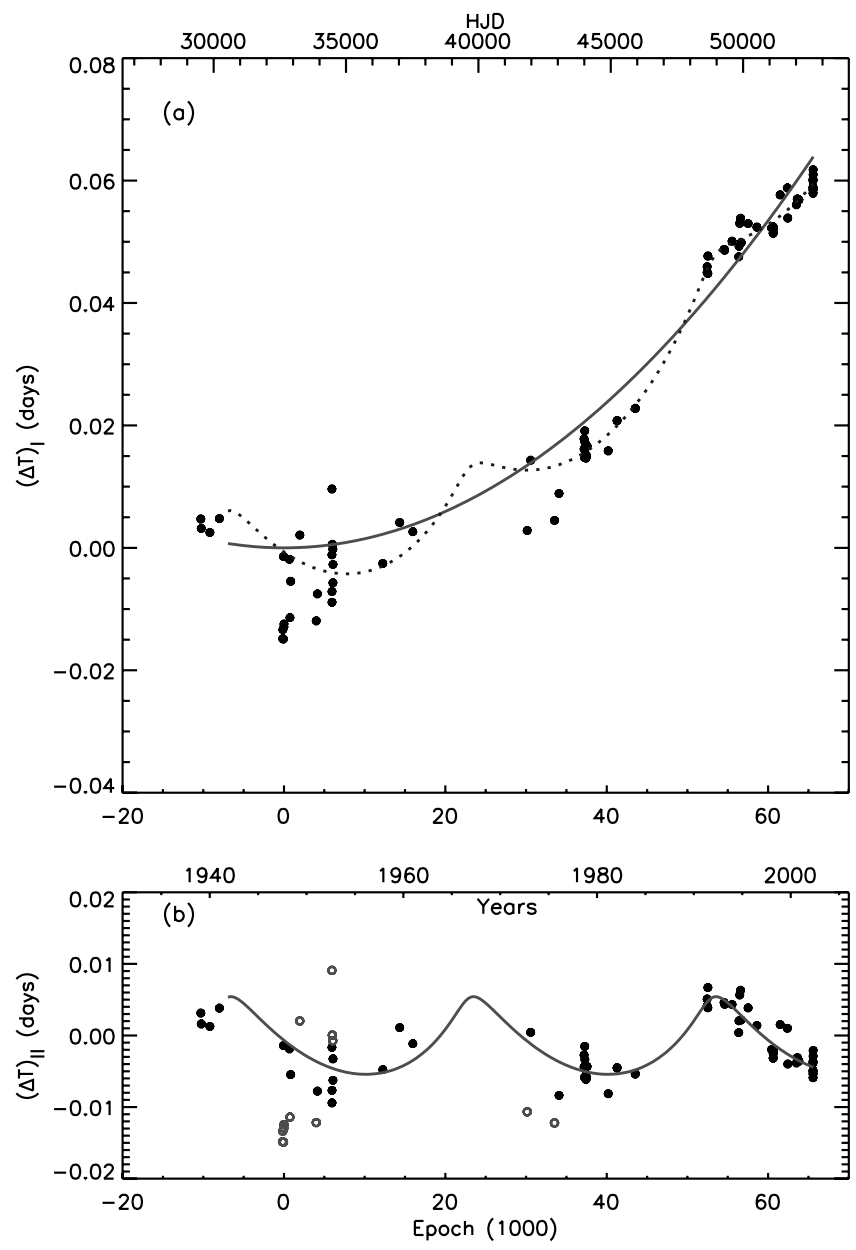

FIG. 1.- $(a)$ The $\triangle T_{\mathrm{I}}$ diagram of the times of mid-eclipse for BB Peg. The solid line shows the parabolic variation, and the dashed line shows a parabolic variation superposed on the variation due to the tertiary component. (b) The $\triangle T_{\mathrm{II}}$ residuals after the subtraction of parabolic change shown in $(a)$. [See the electronic edition of the Journal for a color version of this figure.]
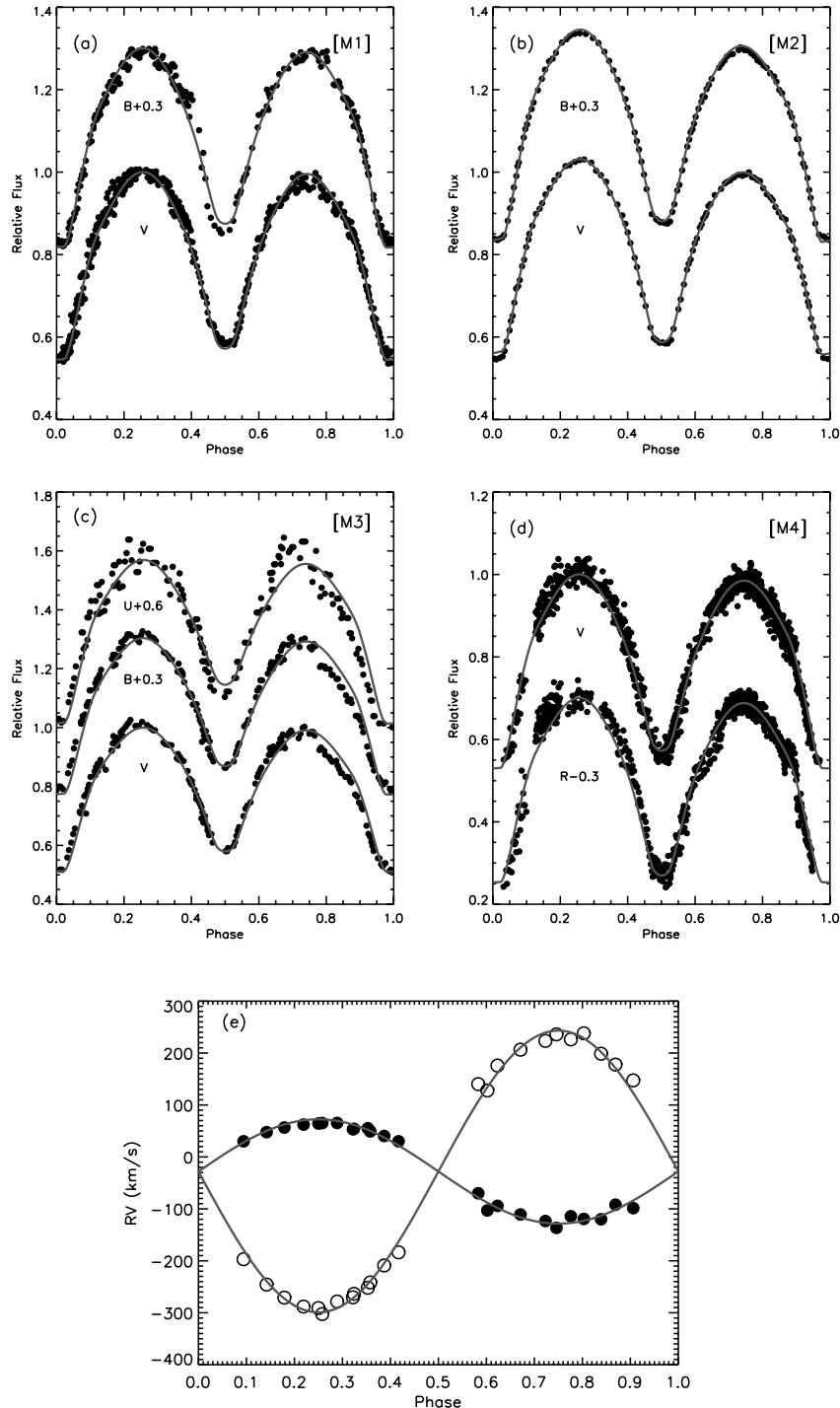

Fig. 2.- Observed and computed light curves of BB Peg. For the sake of comparison the light curves in the $U, B$, and $R$ bands are shifted by values of $+0.6,+0.3$, and -0.3 in intensity. (e) Radial velocities from Lu \& Rucinski (1999) and the computed curve through our simultaneous solution. See the text for details. [See the electronic edition of the Journal for a color version of this figure.]

ponent $T_{2}$, luminosities of the primary component $L_{1}(U, B, V, R)$, potential of the common surface $\Omega$, and spot parameters (latitude, longitude, size, and temperature factor) were adjustable parameters. The results are given in Table 4 . Weights for the different sets of data were determined by the scatter of the observations. In all the analyses the $B, V$, and $R$ filters were given 2 times higher weight than the $U$ filter to take their much better dispersion into account. The computed light curves (solid lines) obtained along with the parameters given in Table 4 were compared with all the observed light curves shown in Figures $2 a-2 d$. The synthetic light curves were created with the LC program.

The obtained parameters for the light curves are given in Table 4. The results of the different light-curve solution models (M) have been denoted by different numbers. We have assigned M1 in Table 4 to two colors ( $B$ and $V$ ) with light-curve solutions obtained from Cerruti-Sola \& Scaltriti (1980), M2 to two colors ( $B$ and $V$ ) with the light-curve model of Zhai \& Zhang (1979; the mean values are taken from Leung et al. 1985), M3 to three colors $(U, B$, and $V)$ with light curves that were obtained by 
TABLE 4

The Photometric Elements of BB Peg

\begin{tabular}{|c|c|c|c|c|}
\hline Parameter $^{\mathrm{a}}$ & M1 & M2 & M3 & M4 \\
\hline \multicolumn{5}{|c|}{ Geometric Parameters } \\
\hline$i(\mathrm{deg})$ & $85.3(6)$ & $87.9(1.4)$ & $84.6(9)$ & $85.0(5)$ \\
\hline$V_{\gamma}$ & $-27.8(1.7)$ & $\ldots$ & $-28.0(2.0)$ & $-28.1(2.2)$ \\
\hline a & $2.665(30)$ & $\ldots$ & $2.671(30)$ & $2.664(32)$ \\
\hline$\Omega_{1,2}$ & $6.066(14)$ & $6.045(6)$ & $6.005(20)$ & $6.056(13)$ \\
\hline 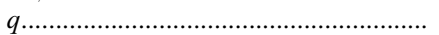 & $2.752(27)$ & $\ldots$ & $2.690(34)$ & $2.702(7)$ \\
\hline Filling factor $(\%)$ & 35 & 38 & 33 & 34 \\
\hline \multicolumn{5}{|c|}{ Fractional Radii of Hot Component } \\
\hline$r_{1 \text { pole } \cdots}$ & $0.2898(12)$ & $0.2888(4)$ & $0.2922(15)$ & $0.2889(19)$ \\
\hline$r_{1}$ side & $0.3042(14)$ & $0.3028(5)$ & $0.3068(19)$ & $0.3030(24)$ \\
\hline$r_{1 \text { back }}$ & $0.3490(27)$ & $0.3450(10)$ & $0.3522(34)$ & $0.3457(45)$ \\
\hline \multicolumn{5}{|c|}{ Fractional Radii of Cool Component } \\
\hline$r_{2}$ pole & $0.4541(11)$ & $0.4499(4)$ & $0.4529(14)$ & $0.4507(16)$ \\
\hline$r_{2}$ side & $0.4894(15)$ & $0.4839(5)$ & $0.4881(19)$ & $0.4849(22)$ \\
\hline$r_{2}$ back & $0.5209(20)$ & $0.5145(7)$ & $0.5200(25)$ & $0.5157(30)$ \\
\hline \multicolumn{5}{|c|}{ Radiative Parameters } \\
\hline$T_{1}{ }^{*}(\mathrm{~K})$ & 6250 & 6250 & 6250 & 6250 \\
\hline$T_{2}(\mathrm{~K})$ & $5905(45)$ & $5945(40)$ & $5760(45)$ & $5955(30)$ \\
\hline Albedo* $\left(A_{1}=A_{2}\right) \ldots \ldots$ & 0.5 & 0.5 & 0.5 & 0.5 \\
\hline Gravity brightening* $\left(g_{1}=g_{2}\right) \ldots \ldots \ldots \ldots$ & 0.32 & 0.32 & 0.32 & 0.32 \\
\hline \multicolumn{5}{|c|}{ Luminosity Ratio $L_{1} /\left(L_{1}+L_{2}\right)(\%)$} \\
\hline$U$ & & $\ldots$ & 45 & $\ldots$ \\
\hline В & 37 & 36 & 41 & $\ldots$ \\
\hline$V$ & 36 & 34 & 38 & 34 \\
\hline$R$ & $\ldots$ & $\ldots$ & $\ldots$ & 32 \\
\hline \multicolumn{5}{|c|}{ Spot Parameters } \\
\hline Colatitude & $1.24(7)$ & $1.52(3)$ & $1.20(15)$ & $1.05(16)$ \\
\hline 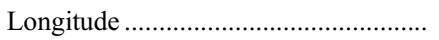 & $4.18(27)$ & $4.36(6)$ & $4.26(40)$ & $4.78(29)$ \\
\hline 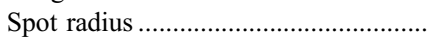 & $0.18(2)$ & $0.34(2)$ & $0.24(3)$ & $0.25(2)$ \\
\hline Spot temperature ................................. & $0.92(2)$ & $0.89(1)$ & $0.93(2)$ & $0.92(2)$ \\
\hline
\end{tabular}

Notes.-The formal $1 \sigma$ errors are given in parentheses. See text for details.

a An asterisk means "fixed."

Awadalla (1988), and M4 to two colors ( $R$ and $V$ ) with light curves obtained in this study. All the results appear to be compatible with each other. Consistency of observations, using the results given in Table 4, with applied models is shown in Figures $2 a-2 d$.

Keeping in mind the possibility of a tertiary component orbiting a third body orbiting the binary system, we assume the third body's $\left(l_{3}\right)$ parameter as a free parameter through the lightcurve solution. However, we could not find meaningful values for the $l_{3}$ parameter throughout the solutions. Likewise, D'Angelo et al. (2006) showed that the light contribution of the third body is tiny $\left(l_{3} / l_{1+2}=0.009\right)$.

\section{RESULTS AND DISCUSSION}

All available light curves in the literature have been solved using the recent WD code, and the results are presented in Table 4. The solutions yielded very similar results. During the process the effective temperature and absolute magnitude of the Sun were taken as $5780 \mathrm{~K}$ and $4.75 \mathrm{mag}$, respectively. In Figure 3 the component parameters are shown on the H-R and mass-radius dia- grams. We show them along with the LTCB systems (Yakut \& Eggleton 2005), whose physical parameters are well known. The results obtained from analyzing BB Peg (Table 5) seem to be in good agreement with the well-known LTCBs. The location of the less massive component in the system indicates that the system is overluminous and oversized, like the other W-subtype secondary stars. Companion stars appear to be below the zero-age main sequence, and the massive component is situated near the terminal-age main sequence. If interstellar absorption is not taken into account, then through the parameters given and using the values given in Table 5 the distance of the system is found to be $361 \pm 25 \mathrm{pc}$. This is consistent with the Hipparcos value (Perryman et al. 1997). The system's distance is derived from the Rucinski \& Duerbeck (1997) period-color-luminosity relation $389 \mathrm{pc}$, which is close to that obtained in this study.

Many contact binaries show an asymmetry in which one maximum is higher than the other (the O'Connell effect); these asymmetries are usually attributed to spots, which we interpret here in a very general sense: they might be due to large cool starspots, to hot regions such as faculae, to gas streams and their 

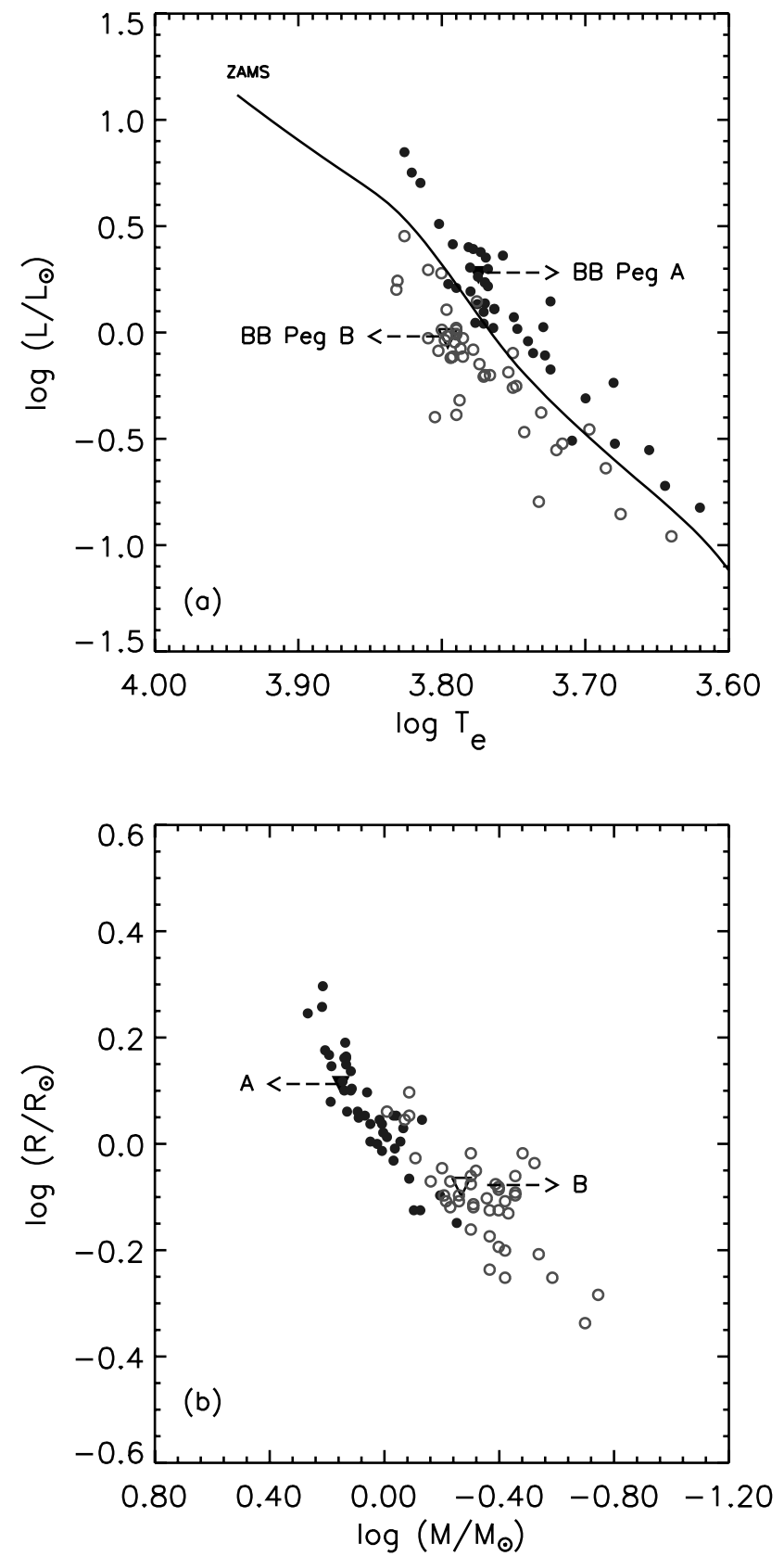

FIG. 3.- $\mathrm{H}-\mathrm{R}$ and mass-radius diagrams showing BB Peg. The filled circles show the primary component of W-type LTCBs, and the open circles represent the secondaries. The zero-age main sequence line is taken from Pols et al. (1995). [See the electronic edition of the Journal for a color version of this figure.] impact on the companion star, or to some inhomogeneities not yet understood (Yakut \& Eggleton 2005). While the asymmetry is apparent in the shape of the light curve of some systems (e.g., YZ Phe; Samec \& Terrell 1995), in others this asymmetry may not be so prominent (e.g, XY Leo; Yakut et al. 2003). The asymmetry in the light curve of BB Peg is modeled with a cold spot on the secondary component (the cooler component with higher mass and radius) of the system. In the model of the light curve denoted by M2 the spot activity appears to be prominent with respect to the other models. The results of the model are summarized in Table 4. In addition, the asymmetry in the light curve is well represented by the model (see Fig. 2).

Figure 1 shows a parabolic variation. Therefore, we have applied a parabolic fit and assume that the mass transfer takes place between the components. The parabolic $\left(\triangle T_{\mathrm{I}}\right)$ curve shown in Figure 1 indicates the existence of mass transfer in the contact system BB Peg. Upward parabolic variation suggests mass transfer from the less massive component (the hotter component in the case of BB Peg) to the more massive component. Equation (2) yields a period increase at a rate of $d P / d t=(3.0 \pm$ $0.1) \times 10^{-8}$ days $\mathrm{yr}^{-1}$. If the period increase is indeed caused by conservative mass transfer, then one can estimate the mass transfer between the components. Using the derived masses, we derive the rate of mass transfer, $(2.4 \pm 0.4) \times 10^{-8} M_{\odot} \mathrm{yr}^{-1}$, from the less massive to the more massive component as in the conservative mass transfer approximation. However, conservative mass transfer is just an optimistic assumption. The nonconservative case is very important in close binary evolution (for details, see Yakut \& Eggleton 2005 and references therein). Analysis of the data, obtained over approximately 25 years, using the WD program indicates a period increase of $(2.9 \pm 0.1) \times$ $10^{-8}$ days $\mathrm{yr}^{-1}$, which is close to that obtained with $O-C$ analysis.

Figure $1 b$ shows the variation of $\triangle T_{\mathrm{II}}$ when the observations are extracted from the parabolic variation. The $\triangle T_{\mathrm{II}}$ variations show a sine-like variation, which implies the existence of a tertiary component orbiting BB Peg on an eccentric orbit. Spectroscopic study of the system shows the existence of an M-type dwarf star about the binary (D'Angelo et al. 2006). Using this information with sine-line variation of the residuals of $(O-C)$, we solved the system under the assumption of the existence of a third body and obtained the values given in Table 3 . The results of the $(O-C)$ analysis show that the third component has a highly eccentric orbit $(e=0.56)$ with about a $30 \mathrm{yr}$ period. Indeed, $(O-C)$ residuals may indicate that the source of this variation could be due to magnetic activity. The orbit of the third body obtained in this study, compared to the data of Pribulla \& Rucinski (2006), appeared to be much more eccentric.

TABLE 5

Absolute Parameters of BB Peg

\begin{tabular}{|c|c|c|}
\hline Parameter & Hot Component & Cool Component \\
\hline 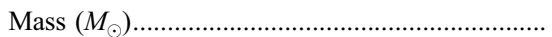 & $0.53(2)$ & $1.42(4)$ \\
\hline 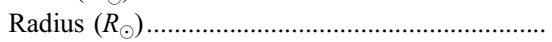 & $0.83(2)$ & $1.29(2)$ \\
\hline 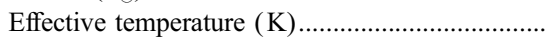 & 6250 & $5950(30)$ \\
\hline Luminosity $\left(L_{\odot}\right)$ & $0.94(6)$ & $1.86(8)$ \\
\hline 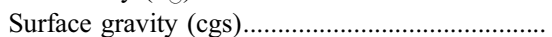 & 4.33 & 4.37 \\
\hline 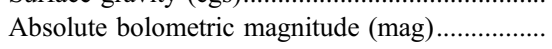 & $4.82_{+0.09}^{-0.08}$ & $4.08_{+0.08}^{-0.13}$ \\
\hline Absolute visual magnitude (mag)......................... & 4.98 & 4.26 \\
\hline 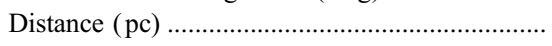 & $361_{+20}^{-25}$ & $361_{+20}^{-25}$ \\
\hline
\end{tabular}

Note.-The standard errors $(1 \sigma)$ in the last digit are given in parentheses. 
On the other hand, using the values given in Tables 3 and 5 one may predict the mass of the tertiary component. By assigning $0.96 \mathrm{AU}$ to $a_{12} \sin i$ and $29.7 \mathrm{yr}$ as the period, one can give the mass function as $0.0010 M_{\odot}$. For orbital inclinations $\left(i_{3}\right)$ of $90,80,50,30$, and 10 the masses of the third body $\left(m_{3}\right)$ are estimated to be $0.161,0.164,0.214,0.341$, and $1.229 M_{\odot}$, respectively. D'Angelo et al. (2006) found a temperature of $3900 \mathrm{~K}$ for the tertiary component and a luminosity ratio $[\beta=$ $\left.l_{3} /\left(l_{1}+l_{2}\right)\right]$ of 0.009 . Following this information with the deduced luminosities given in this study, one may give the radius of the third body as $0.33 R_{\odot}$. The $M \simeq 0.978 R$ relationship is deduced using the 10 well-known M-type dwarf stars given in the study of López-Morales \& Ribas (2005), then the tertiary body's mass of $0.32 M_{\odot}$ is found. Taking into consideration that value of mass, the orbital inclination of the third body is found to be $35^{\circ}$. Useful observations of BB Peg throughout the next decade will help to determine the accurate orbital parameters of the third body from the $O-C$ diagram.

We are grateful to C. Aerts, who has helped to improve the final version of the paper with her comments and suggestions. We thank Robert Smith for his suggestions, which improved the language of the manuscript. We are very grateful to an anonymous referee for comments and helpful, constructive suggestions which helped us to improve the paper. This study was supported by the Ege University Research Fund and TÜBITAK National Observatory. K. Y. acknowledges support by the Research Council of the University of Leuven under a DB fellowship.
Agerer, F., Dahm, M., \& Hübscher, J. 1999, Inf. Bull. Variable Stars, 4712, 1 2001, Inf. Bull. Variable Stars, 5017, 1

Agerer, F., \& Hübscher, J. 1996, Inf. Bull. Variable Stars, 4382, 1 1998a, Inf. Bull. Variable Stars, 4562, 1 1998b, Inf. Bull. Variable Stars, 4606, 1

Awadalla, N. S. 1988, Ap\&SS, 140, 137

Bakıș, V., Bakıș, H., Erdem, A., Çiçek, C., Demircan, O., \& Budding, E. 2003, Inf. Bull. Variable Stars, 5464, 1

Cerruti-Sola, M., Milano, L., \& Scaltriti, F. 1981, A\&A, 101, 273

Cerruti-Sola, M., \& Scaltriti, F. 1980, A\&AS, 40, 85

D’Angelo, C., van Kerkwijk, M. H., \& Rucinski, S. M. 2006, AJ, 132, 650

Demircan, O., et al. 2003, Inf. Bull. Variable Stars, 5364, 1

Derman, E., Yılmaz, N., Engin, S., Aslan, Z., Aydın, C., \& Tüfekcioğlu, Z. 1982, Inf. Bull. Variable Stars, 2159, 1

Diethelm, R. 1973, Rocznik Astron. Obs. Krakowskiego, 44, 102 . 1976, Rocznik Astron. Obs. Krakowskiego, 47, 96 1977, Rocznik Astron. Obs. Krakowskiego, 48, 100

Drozdz, M., \& Ogłoza, W. 2005, Inf. Bull. Variable Stars, 5623, 1

Giuricin, G., Mardirossian, F., \& Mezzetti, M. 1981, Astron. Nachr., 302, 285

Hoffmeister, C. 1931, Astron. Nachr., 242, 129

Hrivnak, B. J. 1990, BAAS, 22, 1291

Hübscher, J. 2005, Inf. Bull. Variable Stars, 5643, 1

Leung, K.-C., Zhai, D., \& Zhang, Y. 1985, AJ, 90, 515

Locher, K. 1973, Suppl. Annu. Cracoviense, 44, 102

López-Morales, M., \& Ribas, I. 2005, ApJ, 631, 1120

Lu, W., \& Rucinski, S. M. 1999, AJ, 118, 515

Lucy, L. B. 1967, Z. Astrophys., 65, 89

Müyesseroğlu, Z., Gürol, B., \& Selam, S. O. 1996, Inf. Bull. Variable Stars, 4380, 1

\section{REFERENCES}

Nelson, R. H. 2002, Inf. Bull. Variable Stars, 5224, 1

Ogłoza, W. 1997, Inf. Bull. Variable Stars, 4534, 1

Perryman, M. A. C., et al. 1997, The Hipparcos and Tycho Catalogues (ESA SP-1200; Noordwijk: ESA)

Pols, O. R., Tout, C. A., Eggleton, P. P., \& Han, Z. 1995, MNRAS, 274, 964

Pribulla, T., \& Rucinski, S. M. 2006, AJ, 131, 2986

Qian, S. 2001, MNRAS, 328, 635

Rucinski, S. M. 1969, Acta Astron., 19, 245

Rucinski, S. M., \& Duerbeck, H. W. 1997, PASP, 109, 1340

Samec, R. G., \& Terrell, D. 1995, PASP, 107, 427

Samolyk, G. 1999, Observed Minima Timings of Eclipsing Binaries, 5 (Cambridge: AAVSO)

Terrell, D., \& Wilson, R. E. 2005, Ap\&SS, 296, 221

Tsessevich, V. P. 1954, Odessa Izv., 4, 271

van Hamme, W. 1993, AJ, 106, 2096

Whitney, B. S. 1943, AJ, 50, 131 1959, AJ, 64, 258

Wilson, R. E. 1994, PASP, 106, 921

Wilson, R. E., \& Devinney, E. J. 1971, ApJ, 166, 605

Wood, D. B. 1972, A Computer Program for Modeling Non-Spherical Eclipsing Binary Systems (Greenbelt: GSFC)

Yakut, K., \& Eggleton, P. P. 2005, ApJ, 629, 1055

Yakut, K., İbanoğlu, C., Kalomeni, B., \& Değirmenci, Ö. L. 2003, A\&A, 401, 1095

Zessewitsch, W. 1939, in Princeton Contrib. 19

Zhai, D. S., \& Zhang, Y. X. 1979, Xexue Tongbao, 21, 895

Zola, S., et al. 2005, Acta Astron., 55, 389 